\title{
Leptin, adiponectin and serotonin levels in lean and obese dogs
}

\author{
Hyung-Jin Park', Sang-Eun Lee ${ }^{2}$, Jung-Hyun $\mathrm{Oh}^{3}$, Kyoung-Won Seo ${ }^{1}$ and Kun-Ho Song ${ }^{1 *}$
}

\begin{abstract}
Background: Serotonin (5-hydroytryptamine or $5 \mathrm{HT}$ ) is associated with numerous behavioral and psychological factors and is a biochemical marker of mood. $5 \mathrm{HT}$ is involved in the hypothalamic regulation of energy consumption. $5 \mathrm{HT}$ controls appetite in the central nerve system (CNS) and stimulates intestinal mobility. There are few studies looking at the role of $5 \mathrm{HT}$ and the relationship between peripheral circulating serotonin and obesity. The aim of this study was to find any differences in leptin, adiponectin, and $5 \mathrm{HT}$ between lean and obese dogs and to identify correlations among these factors.

Results: Leptin, triglyceride (TG) and cholesterol levels were higher in the obese group (all $p<0.01$ ). Adiponectin and $5 \mathrm{HT}$ levels were higher in the lean group compared to the obese group $(p<0.01)$. Leptin $(r=0.628, p<0.01)$, $\mathrm{TG}(r=0.491, \mathrm{p}<0.01)$ and cholesterol $(r=0.419, \mathrm{p}<0.01)$ were positively correlated with body condition score (BCS), and adiponectin $(r=-0.446, \mathrm{p}<0.01)$ and $5 \mathrm{HT}(r=-0.490, \mathrm{p}<0.01)$ were negatively correlated with BCS. Leptin was negatively correlated with adiponectin $(r=-0.294, \mathrm{p}<0.01)$ and $5 \mathrm{HT}(r=-0.343, \mathrm{p}<0.01)$. 5HT was negatively correlated with leptin $(r=-0.343, \mathrm{p}<0.01)$, TG $(r=-0.268, \mathrm{p}<0.05)$ and cholesterol $(r=-0.357, \mathrm{p}<0.05)$.

Conclusions: $5 \mathrm{HT}$ is an important appetite control neurotransmitter, but there are limited studies for $5 \mathrm{HT}$ levels related to obesity in dogs. To the best of our knowledge, this is the first study to evaluate peripheral $5 \mathrm{HT}$ levels in obese dogs. From this research, we can assume that $5 \mathrm{HT}$ may be correlated with canine obesity. Further studies will be needed to further elucidate the role of low serum $5 \mathrm{HT}$ levels in canine obesity.
\end{abstract}

Keywords: Adiponectin, Leptin, Obese dog, Serotonin

\section{Background}

Obesity is a disease characterized by excessive adipose tissue accumulation in the body. It is a common nutritional problem in small animal medicine [1,2]. Ideally, fat mass accounts for approximately $15 \%$ to $20 \%$ in dogs and cats $[3,4]$. Pets are considered overweight when body weight exceeds ideal body weight by $10 \%$ to $20 \%$, and pets are considered obese when body weight exceeds ideal body weight by $20 \%$ to $30 \%$ [4]. Worldwide, approximately $25 \%$ to $35 \%$ of adult cats and $35 \%$ to $40 \%$ of adult dogs are overweight or obese [5,6]. Middle-aged neutered male cats and middle-aged spayed female dogs are at the highest risk for obesity [7]. According to Lund et al. [8], some purebred dogs including Shetland Sheepdogs, Golden Retrievers, Dachsunds, Cocker Spaniels, and Rottweilers

\footnotetext{
* Correspondence: songkh@cnu.ac.kr

${ }^{1}$ Laboratory of Veterinary Internal Medicine, College of Veterinary Medicine,

Chungnam National University, Daejeon 305-764, South Korea

Full list of author information is available at the end of the article
}

have a higher risk of obesity than other breeds. Canine obesity is associated with several health conditions such as insulin resistance, pancreatitis, cruciate ligament rupture, lower urinary tract disease, oral disease, neoplasia, osteoarthritis and decreased longevity [9,10]. Additionally, obesity could be risk factors for brachycephalic syndrome and musculoskeletal problems and it may increase risks associated with anesthesia [7]. Leptin was the first identified adipokine and has a role of regulating body fat mass through appetite control and increased energy metabolism [11]. Restriction of food intake results in a suppression of leptin levels, which is returned by refeeding [11]. Circulating leptin levels correlates positively with adipose tissue mass and exogenous leptin replacement decreases fastinduced hyperphagia [11]. Circulating leptin interacts with peripheral $5 \mathrm{HT}$ and decreases appetite [3]. The majority of obese animals and humans have high serum leptin levels, which suggests leptin resistance [11]. Leptin resistance results from a signaling defect in leptin-responsive 
hypothalamic neurons and impaired transport into the brain [11]. Obesity can be a cause of leptin resistance, but a lack of sensitivity to circulating leptin may also induce obesity $[11,12]$. Adiponectin is believed to be produced by mature adipocytes and it contributes to increased insulin sensitivity, decreased blood glucose, and decreased tissue triglyceride (TG) content in the liver and muscle [12]. Related to obesity, adiponectin has a negative correlation with obesity [12]. The decreasing of adiponectin in obesity is more severe with visceral than subcutaneous adiposity in human and the composition of adiponectin is also changed. Increased production of pro-inflammatory cytokines such as TNF- $\alpha$ and IL-6 with increased fat mass may inhibit adiponectin gene expression [12]. Serotonin (5-hydroytryptamine or 5HT) is associated with numerous behavioral and psychological factors and is a biochemical marker of mood [13,14]. $5 \mathrm{HT}$ is involved in the hypothalamic regulation of energy consumption and 5HT levels in the central nervous system (CNS) are influenced by energy conditions [15]. In the CNS, 5HT has a hypophagic effect owing to an inhibitory interaction with the orexigenic system through hypocretins and neuropeptide Y (NPY). 5HT also likely has a stimulatory effect on the anorexigenic melanocortin system [16]. Concerning interactions among leptin and $5 \mathrm{HT}$, a previous mouse model study reported that peripheral leptin levels were reduced by $5 \mathrm{HT}$, and $5 \mathrm{HT}$ exerted a direct effect on adipocytes and regulated leptin release from adipocytes [15]. Few studies have been published looking at the role of $5 \mathrm{HT}$ and the relationship between peripheral circulating serotonin and obesity $[14,15]$. There have been no studies performed to evaluate peripheral 5 HT levels in obese dogs until now. The aim of this study was to identify differences and correlations among peripheral concentrations of leptin, adiponectin, and 5HT between lean and naturally obese dogs.

\section{Methods}

\section{Ethics statement}

Blood samples of dogs owned by private individuals were used in the present study. The sample collection protocol was approved by Laboratory Animals of Chungnam National University committee (approved No. CNU 00370) and the investigators adhered to the Guide for the Care and Use of Laboratory Animals of Chungnam National University.

\section{Animals and sampling}

A total of 100 healthy dogs (age range: 1 to 15 years-old; mean age: 7 years) owned by clients of Chungnam National University Veterinary Medicine Teaching Hospital were recruited to be in the study from March 2012 to February 2013. Before examination, informed client consent was obtained and we adhered to a high standard of veterinary care. Owners were asked to have their dogs fast for 12 hours prior to presentation for blood sampling. One investigator weighed and examined each dog to screen for potential underlying inflammatory conditions. The same investigator determined a body condition score (BCS) and assigned the dog to either the control group (BCS 4-5/9) or the obese group (BCS 7.5-9/9) utilizing a 9-point BCS system [17]. A screening test for overall health included a physical examination, along with history taking, complete blood count (CBC), serum biochemistry, electrolyte analysis, total thyroxine (tT4), and adrenocorticotropic hormone (ACTH) assay. After the screening test, 18 dogs were excluded in this study due to underlying disease including liver failure, heart disease and hyperadrenocorticism. Also, dogs that were receiving serotonergic drugs, such as fluoxetine or being fed serotonincontaining food, such as bananas, tomatoes, pineapples, or walnuts were excluded from this study. Finally, 82 healthy dogs were enrolled for this research (Table 1).

\section{Sample analysis}

For adipokine analyses, we collected blood by venipuncture using minimal restraint from the jugular vein of dogs that were deemed healthy based on history and physical examination. A fraction of the collected blood was placed in an EDTA tube for a $\mathrm{CBC}$. The remaining blood was allowed to clot at room temperature for 30 minutes and then centrifuged at 2,500 rpm for 15 minutes. Serum and plasma samples were frozen and stored at $-80^{\circ} \mathrm{C}$, and until analysis of adipokines, 5HT, tT4, cortisol, TG and cholesterol levels.

\section{Sandwich enzyme-linked immunosorbent assay and hormone assay}

Serum leptin and adiponectin levels were measured according to the manufacturer's protocol using a canine leptin commercial sandwich enzyme-linked immunosorbent assay (ELISA) kit (Millipore, Billerica, MA, USA) and canine adiponectin commercial ELISA kit (Milipore, Billerica, MA, USA). All samples were tested in duplicate. Serum tT4 and cortisol levels were quantified using an Immulite 1000 immunoassay analyzer (Siemens Medical Diagnostics, Los Angeles, CA, USA). Plasma 5HT concentrations were measured by a commercially available ELISA kit (Serotonin EIA Kit, Enzo Life Sciences Inc, MI, USA) according to the manufacturer's instructions [18].

\section{Statistical analysis}

Statistical analyses were performed by a commercially available computer-based software program (IBM SPSS Statistics 20.0.0, SPSS Inc., Chicago, IL USA). Age, body weight, and BCS results are presented as means with a standard error. Serum leptin, adiponectin, 5HT, TG, cholesterol, tT4, and cortisol levels are presented as 
Table 1 Profile of dogs in lean and obese groups (Mean \pm SE)

\begin{tabular}{|c|c|c|c|c|c|}
\hline & Age & Body weight & BCS & Gender & Breed \\
\hline \multirow[t]{8}{*}{ Lean group } & $4.12 \pm 2.77$ & $5.47 \pm 0.23$ & $4.32 \pm 0.07$ & Male (4) & Shih-Tzu (5) \\
\hline & & & & Male & Poodle (3) \\
\hline & & & & Castrated (9) & Maltese (3) \\
\hline & & & & Female (13) & Mongrel (12) \\
\hline & & & & Female spayed (15) & Schnauzer (3) \\
\hline & & & & & Cocker spaniel (1) \\
\hline & & & & & Yorkshire terrier (1) \\
\hline & & & & & Beagle (13) \\
\hline \multirow[t]{12}{*}{ Obese group } & $7.07 \pm 3.20$ & $10.73 \pm 1.25$ & $8.09 \pm 0.09$ & Male (1) & French bulldog (1) \\
\hline & & & & Male & Shih-Tzu (13) \\
\hline & & & & Castrated (18) & Cocker spaniel (5) \\
\hline & & & & Female (10) & Poodle (3) \\
\hline & & & & Female spayed (12) & Mongrel (2) \\
\hline & & & & & Golden retriever (2) \\
\hline & & & & & Yorkshire terrier (4) \\
\hline & & & & & Beagle (2) \\
\hline & & & & & Maltese (4) \\
\hline & & & & & Dachshund (1) \\
\hline & & & & & Jindo (1) \\
\hline & & & & & Chihuahua (1) \\
\hline
\end{tabular}

means with a standard error and 95\% confidence intercal. A $P$ value of $<0.05$ was considered significant. Age, BCS, leptin, adiponectin, 5HT, total thyroxine (tT4), cortisol, platelets, TG and cholesterol were compared between the lean group and the obese group using the independent $t$-test. The correlation between variables including age, sex, platelets, leptin, adiponectin, 5HT, TG, cholesterol, tT4, cortisol, and BCS were assessed by Pearson's correlation coefficients.

\section{Results}

\section{Leptin, adiponectin and $5 \mathrm{HT}$ levels in the lean and} obese groups

In this study, dogs were separated by BCS into lean and obese groups. Each group had 41 dogs. In the lean group (male, $\mathrm{n}=13$; female, $\mathrm{n}=28$ ), the average age was 4.12 years, the average body weight was $5.47 \mathrm{~kg}$, and the average BCS was 4.32. In the obese group (male, $\mathrm{n}=19$; female, $n=22$ ), the average age was 7.07 years, the average body weight was $10.73 \mathrm{~kg}$, and the average BCS was 8.09. The distributions of BCS and gender in each group are presented in Table 1. Obesity-related parameters, including leptin, adiponectin and 5HT levels, are presented in Table 2 . The obese group showed significantly higher body weights and BCS (both $\mathrm{p}<0.01$ ). Leptin, TG, and cholesterol levels were higher in the obese group than in the lean group $(\mathrm{p}<0.01)$. Adiponectin and 5HT levels were higher in the lean group than the obese group ( $\mathrm{p}<0.01$ ). The distribution of plasma 5 HT concentration is shown in Figure 1. No significant differences were found in $\mathrm{tT} 4$ or cortisol between the lean and obese groups. To evaluate the effect of sex or being castrated/ spayed, we divided animals intact and castrated or spayed within the lean and obese groups. In the obese group, spayed females had a lower level of $5 \mathrm{HT}$ than the intact female group (Table 3). The general tendency of the obesity related parameter was not influenced by gender status (Table 3). To estimate the effect of aging on obesity related parameters, the dogs were divided into two groups (young: < 8 years old; old: $>8$ years old) and within each group, we created two subgroups (lean vs. obese group). Regardless of age, the lean group showed a lower level of BCS and leptin, and a higher level of 5HT than the obese group (Table 4).

\section{Correlation between variables}

Leptin $(r=0.628, \mathrm{p}<0.01)$, TG $(r=0.491, \mathrm{p}<0.01)$ and cholesterol $(r=0.419, \mathrm{p}<0.01)$ levels were positively correlated with BCS and adiponectin $(r=-0.446, \mathrm{p}<0.01)$ and 5HT $(r=-0.490 ; \mathrm{p}<0.01)$ levels were negatively correlated with BCS (Figure 2). Leptin was negatively correlated with adiponectin $(r=-0.294 ; \mathrm{p}<0.01)$ and 5 HT $(r=-0.343$; $\mathrm{p}<0.01)$, but leptin was positively correlated with cholesterol $(r=0.516 ; \mathrm{p}<0.01)$ (Figure 3$)$. 
Table 2 Obesity parameter, adipokines (leptin and adiponectin) and serotonin levels between lean and obese groups (Mean $\pm \mathrm{SE}, \mathbf{9 5 \%}$ confidence interval)

\begin{tabular}{|c|c|c|c|c|c|}
\hline & & & & & P-value \\
\hline & Mean \pm SE & $95 \% \mathrm{Cl}$ & Mean \pm SE & $95 \% \mathrm{Cl}$ & \\
\hline BCS & $4.31 \pm 0.07$ & 4.164 .45 & $8.07 \pm 0.09$ & 7.898 .25 & $<0.01$ \\
\hline Leptin (ng/mL) & $2.69 \pm 1.08$ & 1.913 .46 & $10.27 \pm 1.20$ & 7.9112 .63 & $<0.01$ \\
\hline Adiponeptin $(\mu \mathrm{g} / \mathrm{mL})$ & $12.18 \pm 1.09$ & 10.0514 .31 & $6.23 \pm 0.79$ & 4.667 .78 & $<0.01$ \\
\hline Serotonin (ng/mL) & $792.96 \pm 102.45$ & 749.49839 .47 & $560.43 \pm 245.95$ & 491.28623 .19 & $<0.01$ \\
\hline Triglyceride (mg/dL) & $51.53 \pm 29.03$ & 41.7861 .28 & $138.64 \pm 125.46$ & 92.13180 .95 & $<0.01$ \\
\hline Cholesterol (mg/dL) & $211.03 \pm 73.80$ & 186.23235 .82 & $289.97 \pm 112.93$ & 254.86325 .88 & 0.01 \\
\hline Total T4 ( $\mu \mathrm{g} / \mathrm{dL})$ & $1.74 \pm 0.66$ & 1.501 .97 & $1.55 \pm 0.55$ & 1.361 .726 & 0.19 \\
\hline Cortisol ( $\mu \mathrm{g} / \mathrm{dL})$ & $4.61 \pm 2.36$ & 3.785 .44 & $5.39 \pm 3.43$ & 4.266 .52 & 0.29 \\
\hline
\end{tabular}

$\mathrm{Cl}$; confidence interval.

\section{Discussion}

In the current research, we found that obese dogs had lower $5 \mathrm{HT}$ and adiponectin levels and higher leptin levels than lean dogs. TG and cholesterol levels were high in the obese group compared with the lean group. Body fat is no longer considered simply as energy storage. Adipocytes produce many cytokines and hormones referred to as fat-derived peptides [12]. Adipokines include adiponectin, leptin, resistin, amyloid A, transforming growth factor $\beta$, tumor necrosis factor and interleukin-6 $[7,12,19]$. Currently, there is much interest in the role of adipokines

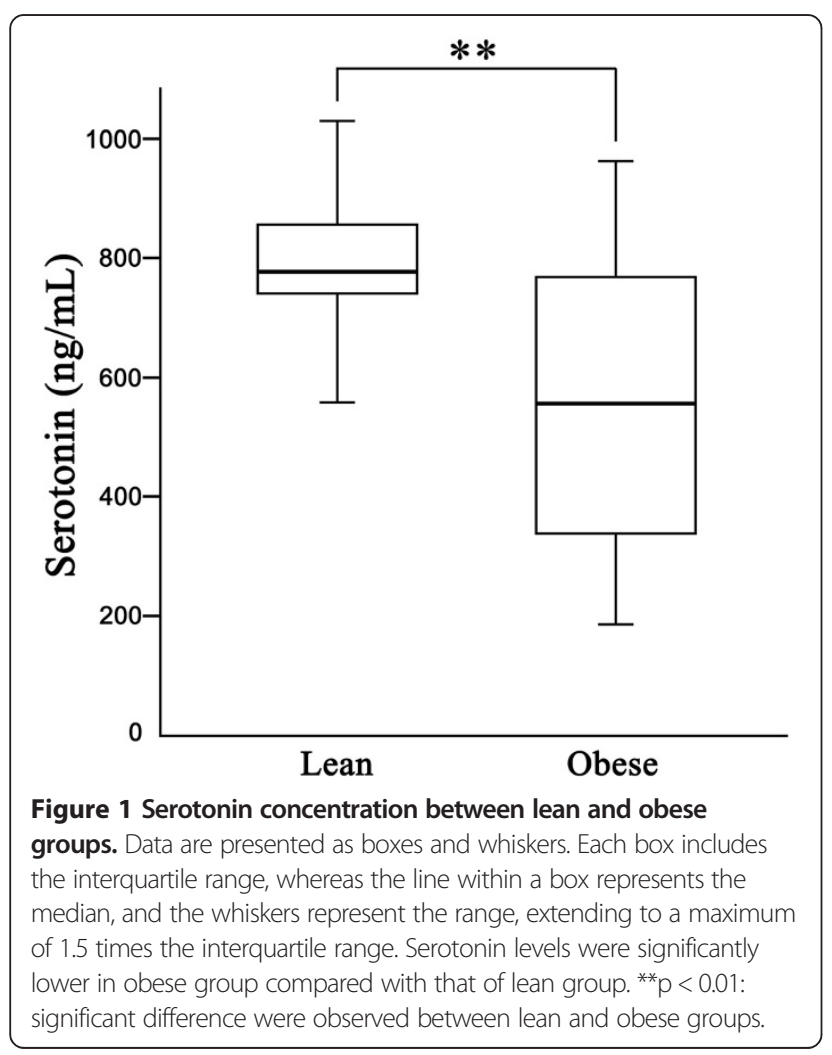

in canine obesity [19]. Circulating leptin levels are positively correlated with adipose tissue mass, and exogenous leptin replacement decreases fast-induced hyperphagia [11]. However, the majority of obese animals and humans have high serum leptin levels, which suggests leptin resistance [11]. In this study, the serum leptin levels of dogs in the obese group were higher than those in the lean group, and adiponectin levels in the obese group were lower than those in the lean group (Table 2). Obesity can be a cause of leptin resistance, but a lack of sensitivity to circulating leptin may also induce obesity $[11,20]$.

Middle-aged neutered male cats and middle-aged spayed female dogs have a high risk of being overweight or obese $[8,21]$. With aging, lean body mass gradually declines, resulting in a reduced basal metabolic rate (BMR) and reduced total daily energy needs. If accompanied by reduced exercise, the loss of lean body mass will be exacerbated. This study revealed no significant differences in obesity-related parameters, with the exception of cholesterol, between young and old dogs. However, spayed female dogs had a significantly higher BCS than intact females and this is the same result as a previous study [8]. Neutering decreases the BMR by $25 \%$ to $33 \%$ [22]. Most dog owners are unaware of the altered metabolic activity after ovariohysterectomy and do not decrease the food supply, which leads to increased food intake in dogs. This feeding behavior is often accompanied by decreased physical activity and, consequently, spayed female dogs gain weight easily.

In our study, the obese group had higher TG and cholesterol levels than the lean group. However, in the obese group, the average TG level (138.64) did not exceed $1000 \mathrm{mg} / \mathrm{dL}$ and the average cholesterol level (289.97) was less than $750 \mathrm{mg} / \mathrm{dL}$. The goal of hyperlipidemia treatment is to maintain plasma lipid concentrations under a level at which health problems are likely to occur. Dietary intervention is recommended in dogs that 
Table 3 Obesity parameter, adipokines, and serotonin levels according to sex (Mean \pm SE)

\begin{tabular}{|c|c|c|c|c|c|}
\hline & & \multicolumn{2}{|c|}{ Males } & \multicolumn{2}{|c|}{ Females } \\
\hline & & $\begin{array}{l}\text { Intact } \\
(\mathrm{N}=4)\end{array}$ & $\begin{array}{l}\text { Castrated } \\
\qquad(\mathrm{N}=9)\end{array}$ & $\begin{array}{c}\text { Intact } \\
(\mathrm{N}=13)\end{array}$ & $\begin{array}{l}\text { Spayed } \\
(\mathrm{N}=15)\end{array}$ \\
\hline \multirow[t]{8}{*}{ Lean group } & BCS & $4.25 \pm 0.25$ & $4.44 \pm 0.17$ & $4.0 \pm 0$ & $4.53 \pm 0.13$ \\
\hline & Leptin (ng/mL) & $5.06 \pm 2.85$ & $2.60 \pm 0.48$ & $1.59 \pm 0.18$ & $2.88 \pm 0.68$ \\
\hline & Adiponectin $(\mu \mathrm{g} / \mathrm{mL})$ & $10.53 \pm 1.29$ & $11.55 \pm 2.20$ & $14.31 \pm 2.61$ & $11.14 \pm 1.42$ \\
\hline & Serotonin (ng/mL) & $871.31 \pm 61.31$ & $736.0 \pm 43.98$ & $739.49 \pm 15.69$ & $832.21 \pm 22.45$ \\
\hline & Triglyceride (mg/dL) & $64.75 \pm 18.32$ & $42.0 \pm 9.54$ & $38.57 \pm 7.08$ & $51.21 \pm 5.44$ \\
\hline & Cholesterol (mg/dL) & $282.0 \pm 38.02$ & $218.33 \pm 27.36$ & $163.14 \pm 18.02$ & $204.57 \pm 17.45$ \\
\hline & & Intact & Castrated & Intact & Spayed \\
\hline & & $(\mathrm{N}=1)$ & $(\mathrm{N}=18)$ & $(\mathrm{N}=10)$ & $(\mathrm{N}=12)$ \\
\hline \multirow[t]{6}{*}{ Obese group } & BCS & 8 & $8.16 \pm 0.14^{\star \star}$ & $8.10 \pm 0.23^{\star \star}$ & $7.67 \pm 0.22^{\star \star}$ \\
\hline & Leptin (ng/mL) & 11.6 & $11.66 \pm 1.70^{\star \star}$ & $9.91 \pm 3.20^{\star \star}$ & $8.39 \pm 1.91^{\star \star}$ \\
\hline & Adiponectin $(\mu \mathrm{g} / \mathrm{mL})$ & 5.2 & $5.92 \pm 1.07^{\star}$ & $6.80 \pm 1.38^{\star \star}$ & $6.29 \pm 1.99^{\star}$ \\
\hline & Serotonin (ng/mL) & 622.45 & $533.26 \pm 58.89^{\star \star}$ & $682.14 \pm 59.95$ & $478.0 \pm 74.06^{*}, \star \star$ \\
\hline & Triglyceride (mg/dL) & 288 & $154.16 \pm 35.13^{\star}$ & $148.57 \pm 45.48^{\star}$ & $95.91 \pm 14.08^{\star}$ \\
\hline & Cholesterol (mg/dL) & 325 & $301.38 \pm 23.22^{\star}$ & $240.20 \pm 24.14^{\star}$ & $296.72 \pm 49.91^{\star}$ \\
\hline
\end{tabular}

${ }^{*} \mathrm{p}<0.05$ between intact and spayed groups.

$\star_{p}<0.05$ between lean and obese groups.

$\star \star \mathrm{p}<0.01$ between lean and obese groups.

have fasting TG levels greater than $500 \mathrm{mg} / \mathrm{dL}$ or cholesterol levels over $750 \mathrm{mg} / \mathrm{dL}$ [23]. In the present study, the obese group had high TG and cholesterol levels, but the likelihood of health problems induced by hyperlipidemia in these animals is marginal. In this study, the peripheral 5HT levels in the obese group were significantly lower than in the lean group, which is similar to human study results [13]. Furthermore, a negative correlation between leptin and 5HT was observed in this study. In the obese group, spayed female showed lower 5HT levels compared with intact female. In human studies, natural postmenopausal and ovariectomised women had lower 5 HT levels than regularly menstruating women [24]. Estrogen withdrawal alters serotonergic functioning and exogenous estrogen supplementation could increase 5HT levels in postmenopausal women [15,24]. As with human studies, we found a similar phenomenon in spayed obese dogs. 5HT throughout the body influences food consumption by controlling satiety [25]. Therefore, low levels of $5 \mathrm{HT}$ could be a risk factor for obesity due to increased appetite. 5HT has a hypophagic effect in the CNS, and $5 \mathrm{HT}$ concentrations in the peripheral nervous system may not necessarily equate to $5 \mathrm{HT}$ levels or availability in the brain, since $5 \mathrm{HT}$ cannot cross the blood-brain barrier [14]. L-tryptophan, an amino acid and precursor to serotonin is converted to 5-hydroxy-L-tryptophan (5-HTP) and then to serotonin in both the CNS and PNS [26]. Brain tryptophan and serotonin levels are determined by the ratio of plasma tryptophan to other large neutral amino acids (LNAAs), which compete with tryptophan for uptake

Table 4 Obesity parameter, adipokines and serotonin levels according to age (Mean \pm SE)

\begin{tabular}{|c|c|c|c|c|c|c|}
\hline & \multicolumn{2}{|c|}{ Young group $(<8$-year old $)(\mathrm{N}=58)$} & \multirow[b]{2}{*}{ P-value } & \multicolumn{2}{|c|}{ Old group (> 8-year old) $(\mathrm{N}=24)$} & \multirow[b]{2}{*}{ P-value } \\
\hline & $\begin{array}{l}\text { Lean group } \\
\qquad(\mathrm{N}=36)\end{array}$ & $\begin{array}{l}\text { Obese group } \\
\qquad(\mathrm{N}=22)\end{array}$ & & $\begin{array}{l}\text { Lean group } \\
\qquad(\mathrm{N}=5)\end{array}$ & $\begin{array}{l}\text { Obese group } \\
\qquad(\mathrm{N}=19)\end{array}$ & \\
\hline BCS & $4.31 \pm 0.08$ & $8.09 \pm 0.15$ & $<0.01$ & $4.40 \pm 0.24$ & $7.89 \pm 0.16$ & $<0.01$ \\
\hline Leptin (ng/mL) & $2.64 \pm 0.44$ & $10.29 \pm 1.87$ & $<0.01$ & $3.02 \pm 0.66$ & $10.24 \pm 1.47$ & 0.023 \\
\hline Adiponeptin $(\mu \mathrm{g} / \mathrm{mL})$ & $12.28 \pm 1.19$ & $5.83 \pm 0.90$ & $<0.01$ & $11.47 \pm 2.66$ & $6.68 \pm 1.39$ & 0.13 \\
\hline Serotonin (ng/mL) & $794.70 \pm 16.76$ & $587.71 \pm 54.94$ & $<0.01$ & $780.41 \pm 57.01$ & $528.83 \pm 53.80$ & 0.032 \\
\hline Triglyceride (mg/dL) & $48.21 \pm 4.41$ & $150.56 \pm 34.27$ & $<0.01$ & $70.80 \pm 22.19$ & $131.66 \pm 26.08$ & 0.251 \\
\hline Cholesterol (mg/dL) & $205.97 \pm 14.34$ & $276.65 \pm 19.72$ & $<0.01$ & $240.40 \pm 19.50$ & $299.68 \pm 31.85$ & 0.363 \\
\hline Total T4 ( $\mu \mathrm{g} / \mathrm{dL})$ & $1.82 \pm 0.12$ & $1.50 \pm 0.13$ & 0.103 & $1.38 \pm 0.17$ & $1.58 \pm 0.13$ & 0.434 \\
\hline Cortisol ( $\mu \mathrm{g} / \mathrm{dL})$ & $4.42 \pm 0.42$ & $4.80 \pm 0.83$ & 0.652 & $5.54 \pm 1.17$ & $5.97 \pm 0.78$ & 0.793 \\
\hline
\end{tabular}



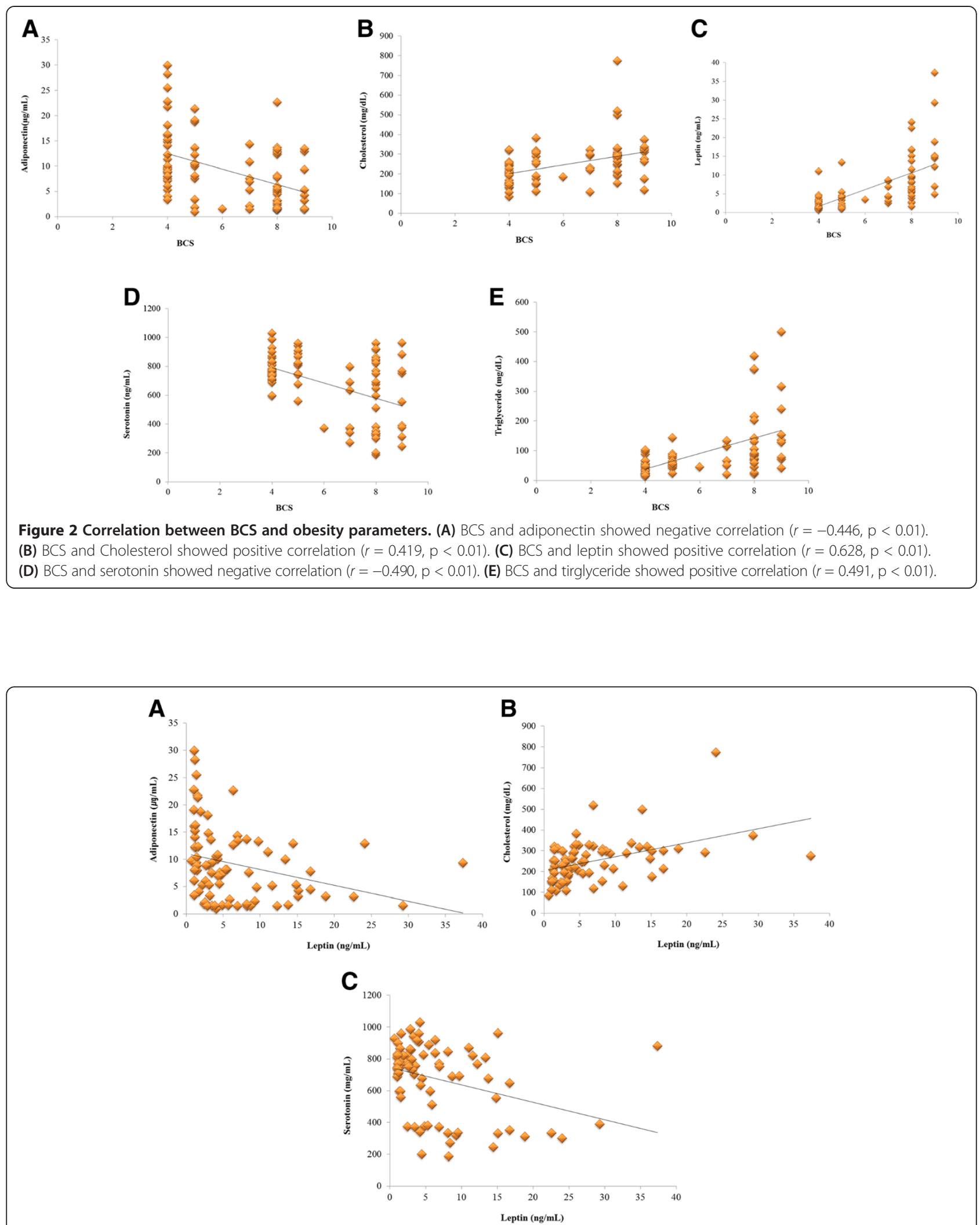

Figure 3 Correlation among leptin, adiponectin, cholesterol and serotonin. (A) Leptin and adiponectin showed negative correlation $(r=-0.294$, $\mathrm{p}<0.01)$. (B) Leptin and Cholesterol showed positive correlation $(r=0.516, p<0.01)$. (C) Leptin and serotonin showed negative correlation ( $r=-0.343$, $p<0.01)$. 
into the brain [14]. After eating carbohydrates, insulin is released, which promotes uptake of the LNAAs, but not tryptophan, into skeletal muscles. This helps tryptophan pass more easily into the brain, which increases serotonin production in the brain $[14,25]$. Increased $5 \mathrm{HT}$ production in the brain from carbohydrate-rich diets can induce mood-enhancing post-ingestion effects that motivate intake of such foods and, consequently, promote weight gain [14]. Circulating leptin interacts with peripheral 5HT and decreases appetite [3]. One mouse model study reported that plasma leptin was reduced by $5 \mathrm{HT}$, and $5 \mathrm{HT}$ exerted a direct effect on adipocytes and regulated leptin release from adipocytes [15]. Moreover, $5 \mathrm{HT}$ is able to down-regulate adiponectin in the mouse adipocyte cell line [27]. Peripheral 5HT concentration of the obese group is significantly lower than the lean group in this study, and this is similar with human study results. Enterochromaffin (EC) cells in the intestinal epithelium release 5HT according to mechanical stimulation, to promote transit [28]. Experimentally a diet-induced obesity model showed decreased 5HT levels with a decreased number of EC cells [11]. The inflammation associated with changes in the GI microbiota is considered as the reason for decreased $5 \mathrm{HT}$ availability in obese status $[28,29]$. $5 \mathrm{HT}$, as a neurotransmitter, controls food satiety, and, therefore, high $5 \mathrm{HT}$ concentrations decrease leptin and adiponectin concentrations. We found that $5 \mathrm{HT}$ is negatively correlated to leptin. Based on the previous result of a mouse model that $5 \mathrm{HT}$ could reduce the secretion of leptin, we can consider the possibility that lowered 5HT failed to properly suppress increasing secretion of leptin [15]. As seen in Figure 3C, however, there are more dogs presenting a high level of $5 \mathrm{HT}$ at a low level of leptin than ones presenting a low level of $5 \mathrm{HT}$ at a high level of leptin. Therefore, further studies would be needed with a larger number of dogs to evaluate the interaction between 5HT and leptin. The low level of adiponectin in the obese group was similar to the results of previous studies [30,31]. Adiponectin was negatively correlated with obesity [32]. The decreased adiponectin level in obesity is more significant in visceral than subcutaneous adiposity in humans, and the composition of adiponectin also changes with location in the body. $5 \mathrm{HT}$ suppresses adiponectin, and, therefore, a high peripheral adiponectin level can induce a low 5HT level. However, we observed low levels of both $5 \mathrm{HT}$ and adiponectin in the obese group in our study.

Through this research, we found that the level of peripheral $5 \mathrm{HT}$ is low in the obese group. Since $5 \mathrm{HT}$ is related to intestinal mobility, we can expect that a lower level of $5 \mathrm{HT}$ could reduce intestinal mobility. The reduced mobility, in turn, could allow gut microorganism to undergo energy harvesting for a longer period, which consequentially could aggravate obesity. Based on this hypothesis, further research is needed to identify that $5 \mathrm{HT}$ treatment could actually activate intestinal mobility and how it might work to reduce obesity. It is possible that humans are becoming obese as a result of overeating in order to maintain serotonin levels and the resulting positive mood. Therefore, serotonin agonists may be a treatment option for obesity in humans [33]. From this research, we found that the $5 \mathrm{HT}$ level of obese dogs was lower than that of lean dogs, therefore, we could assume that a serotonin agonist might be helpful in increasing the $5 \mathrm{HT}$ level in obese dogs. Increased 5HT levels via a serotonin agonist may control appetite and prompt intestinal motility. In human medicine, high levels of 5HT may be dangerous, and is known as serotonin syndrome [34]. Unfortunately, there have been few studies on the relationship between obesity and $5 \mathrm{HT}$ in the veterinary field so far. As obesity is considered to cause several diseases, based on the results of our research, more studies are needed to determine the impact and the mechanism of $5 \mathrm{HT}$ on leptin and adiponectin. Furthermore, as a treatment option for obesity in veterinary medicine, clinical trials of a $5 \mathrm{HT}$ agonist and considerations of adverse effects should be pursued.

There are a few limitations to this study. First of all, concerning the selection of the dogs in this study, the distribution of dogs does not balance between intact and castrated males. For example, there was a relatively fewer number of intact males than castrated males in the obese group. In addition, even though we identified several corrections among adipokines, 5HT, and other obesityrelated parameters, we did not go further to formulate the mechanism of interactions among them. Although we found a significant difference in 5 HT levels between the lean and obese groups, there was also variation within the groups. We tried to control for factors that influence 5HT levels such as platelet, diarrhea and food. However, we could not control emotion, social situation or the rhythm activity of an enrolled subject.

\section{Conclusions}

5HT is an important appetite control neurotransmitter, but there are limited studies regarding 5HT levels related to obesity in veterinary medicine. Overall, we found that peripheral $5 \mathrm{HT}$ levels were lower in obese dogs than lean dogs, and 5HT was negatively correlated with BCS and leptin levels. To the best of our knowledge, this is the first study to evaluate peripheral 5 HT levels in obese dogs.

Competing interests

The authors declare that they have no competing interests.

Authors' contributions

HJP, KWS and KHS participated in the conception and design of this study. HJP and SEL participated in sample collection, laboratory testing and drafting of article. $\mathrm{HO}$, KWS and HJP participated in statistical analysis. KWS, KHS, and SEL participated in critical revisions. All authors read and approved the final manuscript. 


\section{Acknowledgments}

This work was supported by the National Research Foundation of Korea (NRF) grant funded by the Korean Government (MOE) (NRF-2012R1A1A2041697).

\section{Author details}

${ }^{1}$ Laboratory of Veterinary Internal Medicine, College of Veterinary Medicine, Chungnam National University, Daejeon 305-764, South Korea. ${ }^{2}$ Division of Malaria \& Parasitic Diseases, Korea National Institute of Health, Korea Centers for Disease Control and Prevention, Osong-eup, Cheongwon-gun, Chungbuk 363-951, South Korea. ${ }^{3}$ Department of Statistics, Chung-Ang University, Seoul 156-756, South Korea.

Received: 26 November 2013 Accepted: 8 May 2014

Published: 13 May 2014

\section{References}

1. Lund EM, Armstrong PJ, Kirk CA, Klausner JS: Prevalence and risk factors for obesity in adult cats from private US veterinary practices. Int J App/ Res Vet M 2005, 3:88-96.

2. Markwell PJ, Butterwick RF, Wills JM, Raiha M: Clinical studies in the management of obesity in dogs and cats. Int J Obes Relat Metab Disord 1994, 18:39-43.

3. Leibowitz SF, Alexander JT: Hypothalamic serotonin in control of eating behavior, meal size, and body weight. Biol Psychiatry 1998, 44:851-864.

4. Hand MS, Thatcher CD, Remillard RL, Roudebush P, Novotny BJ: Small Animal Clinical Nutrition. 5th edition. Topeka: Mark Morris Institute; 2010.

5. Clarke SP, Mellor D, Clements DN, Gemmill T, Farrell M, Carmichael S, Bennett D: Prevalence of radiographic signs of degenerative joint disease in a hospital population of cats. Vet Rec 2005, 157:793-799.

6. Lund EM, Armstrong PJ, Kirk CA, Klausner JS: Prevalence and risk factors for obesity in adult dogs from private US veterinary practices. Int J Appl Res Vet M 2006, 4:177-186.

7. Towell LT: Practical Weight Management In Dogs And Cats. Blackwell: UK; 2011

8. Lund EM, Armstrong PJ, Kirk CA, Kolar LM, Klausner JS: Health status and population characteristics of dogs and cats examined at private veterinary practices in the United States. J Am Vet Med Assoc 1999, 214:1336-1341.

9. Perez Alenza MD, Peña L, del Castillo N, Nieto Al: Factors influencing the incidence and prognosis of canine mammary tumours. J Small Anim Pract 2000, 41:287-291.

10. Hodge S, Bunting BP, Carr E, Strain JJ, Stewart-Knox BJ: Obesity, whole blood serotonin and sex differences in healthy volunteers. Obes Facts 2012, 5:399-407

11. Wynne K, Stanley S, McGowan B, Bloom S: Appetite control. J Endocrinol 2005, 184:291-318.

12. Radin MJ, Sharkey LC, Holycross BJ: Adipokines: a review of biological and analytical principles and an update in dogs, cats, and horses. Vet Clin Pathol 2009, 38:136-156.

13. Duffy ME, Stewart-Knox BJ, McConville C, Bradbury I, O'Connor J, Hel \& Strain JJ: The relationship between whole-blood serotonin and subjective mood in apparently healthy postmenopausal women. Biol Psychol 2006, 73:165-168.

14. Horácek J, Kuzmiaková M, Höschl C, Andĕl M, Bahbonh R: The relationship between central serotonergic activity and insulin sensitivity in healthy volunteers. Psychoneuroendocrinology 1999, 24:785-794.

15. Stunes AK, Reseland JE, Hauso O, Kidd M, Tommeras K, Waldum HL, Gustafsson Bl: Adipocytes express a functional system for serotonin synthesis, reuptake and receptor activation. Diabetes Obes Metab 2011 13:551-558.

16. Aronne $L$, Thornton-Jones ZD: New targets for obesity pharmacotherapy. Clin Pharmacol Ther 2007, 81:748-752.

17. Laflamme D: Development and validation of a body condition score system for dogs. Canine Prac 1997, 22:10-15.

18. Lacerda CM, Maclea HB, Kisiday JD, Orton EC: Static and cyclic tensile strain induce myxomatous effector proteins and serotonin in canine mitral valves. J Vet Cardiol 2021, 14:223-230

19. Eirmann LA, Freeman LM, Laflamme DP, Michel KE, Satyaraj E: Comparison of adipokine concentrations and markers of inflammation in obese versus lean dogs. Int J Appl Res Vet M 2009, 7:196-205.

20. Pan W, Kastin AJ, Banks WA, Zadina JE: Effects of peptides: a cross-listing of peptides and their central actions published in the journal peptides from 1994 through 1998. Peptides 1999, 20:1127-1138.
21. Laflamme DP, Kuhlman G, Lawler DF: Evaluation of weight loss protocols for dogs. J Am Anim Hosp Assoc 1997, 33:253-259.

22. Root MV, Johnston SD, Olson PN: Effect of prepuberal and postpuberal gonadectomy on heat production measured by indirect calorimetry in male and female domestic cats. Am J Vet Res 1996, 57:371-374.

23. Ford RB: Idiopathic hyperchylomicronemia in miniature schnauzers. J Small Anim Pract 1993, 34:488-492.

24. Gonazles GF, Carrillo C: Blood serotonin levels in postmenopausal women: effects of age and serum oestradiol levels. Maturitas 1993, 17:23-29.

25. Fuemmeler BF, Agurs-Collins TD, McClernon FJ, Kollins SH, Kail ME, Bergen AW, Ashley-Koch AE: Genes implicated in serotonergic and dopaminergic functioning predict BMI categories. Obesity 2008, 16:348-355

26. Zhang X, Beaulieu JM, Sotnikova TD, Gainetdinov RR, Caron MG: Tryptophan hydroxylase-2 controls brain serotonin synthesis. Science 2004, 305:217.

27. Uchida-Kitajima S, Yamauchi T, Takashina Y, Okada-Iwabu M, Iwabu M, Ueki K, Kadowaki T: 5-Hydroxytryptamine $2 \mathrm{~A}$ receptor signaling cascade modulates adiponectin and plasminogen activator inhibitor 1 expression in adipose tissue. FEBS Lett 2008, 582:3037-3044.

28. Bertrand RL, Senadheera S, Tanoto A, Tan KL, Howitt L, Chen H, Murphy TV, Sandow SL, Liu L, Bertrand PP: Serotonin availability in rat colon is reduced during a western diet model of obesity. Am J Physiol Gastrointest Liver Physiol 2012, 303:424-434.

29. Maslowski KM, Vieira AT, Ng A, Kranich J, Sierro F, Yu D, Schilter HC, Rolph MS, Mackay F, Artis D, Xavier RJ, Teixeira MM, Mackay CR: Regulation of inflammatory responses by gut microbiota and chemoattractant receptor GPR43. Nature 2009, 461:1282-1286.

30. Hu E, Liang P, Spiegelman BM: AdipoQ is a novel adipose-specific gene dysregulated in obesity. J Biol Chem 1996, 271:10697-10703.

31. Jeusette IC, Lhoest ET, Istasse LP, Diez MO: Influence of obesity on plasma lipid and lipoprotein concentrations in dogs. Am J Vet Res 2005, 66:81-86.

32. Ishioka K, Omachi A, Sagawa M, Shibata H, Honjoh T, Kimura K, Saito M: Canine adiponectin: cDNA structure, mRNA expression in adipose tissues and reduced plasma levels in obesity. Res Vet Sci 2006, 80:127-132.

33. Taylor JR, Dietrich E, Powell J: Lorcaserin for weight management. Diabetes Metab Syndr Obes 2013, 6:209-216.

34. Dunkley EJ, Isbister GK, Sibbritt D, Dawson AH, Whyte IM: The hunter serotonin toxicity criteria : simple and accurate diagnostic decision rules for serotonin toxicity. QJM 2003, 96:635-642.

\section{doi:10.1186/1746-6148-10-113}

Cite this article as: Park et al:: Leptin, adiponectin and serotonin levels in lean and obese dogs. BMC Veterinary Research 2014 10:113.

\section{Submit your next manuscript to BioMed Central and take full advantage of:}

- Convenient online submission

- Thorough peer review

- No space constraints or color figure charges

- Immediate publication on acceptance

- Inclusion in PubMed, CAS, Scopus and Google Scholar

- Research which is freely available for redistribution
C Biomed Central 